\title{
O Tempo Entre Gerações ${ }^{1}$
}

\section{Eligio Resta}

É atualmente professor de Filosofia do Direito na Faculdade de Direito da Università di Roma TRE. Professor visitante de várias universidades brasileiras e latino-americanas. De 1988 a 2002 foi integrante laico do Conselho Superior da Magistratura, eleito pelo Parlamento, em que foi presidente da Comissão Conciliar, competente pelo Regulamento. Também foi vice-presidente da Comissão de Reforma, da Comissão de Magistratura Honorária e da Comissão de Formação dos Magistrados. É membro do Comitê Científico da ONU sobre temas que versam sobre legalidade. Atualmente faz parte do grupo de estudos internacionais sobre a Constituição Europeia. É diretor de inúmeras revistas sobre Direito, Sociologia e política. Autor de inúmeros livros e artigos científicos. e.resta@ uniroma3.it

\section{Resumo}

0 presente texto pretende demonstrar que não se pode saltar o jogo das gerações; ele é inscrito dentro de vínculos naturais que não podem ser desfeitos. Logo, a indiferença é justificada pela imprescritibilidade que não pode mudar conhecimento e situação. 0 único problema verdadeiro de justiça entre gerações diferentes é posto pela maneira na qual as instituições regulam o acesso aos recursos limitados no tempo, ou seja, agem com a vantagem dada pelas possibilidades históricas. Não nos interessa tanto a vertente ético-política, mesmo sendo relevante, do já robusto discurso sobre a justiça intergeracional, mas sim aquela entendida a partir de Rawls, do caráter simbólico e virtual que cada geração instaura com o seu futuro, partindo do presente. Cruzamento contínuo de sincronia e diacronia, as gerações não podem existir como identidade, senão como referência frequentemente antagônica - à dessemelhança (as outras "gerações"). Assim as suas identidades vivem de uma postura cúmplice no confronto daqueles dos quais se distinguem.

Palavras-chave: Gerações. Justiça intergeracional. Tempo. Futuro.

1 Título original em italiano "Tra generazione”. Tradução de Fabiana Marion Spengler. 


\title{
THE TIME BETWEEN GENERATIONS
}

\begin{abstract}
:
The present text intends to demonstrate that nobody can skip the game of generations; it is written inside of natural ties that cannot be undone. Therefore, the difference is justified by the imprescriptibility that cannot change knowledge and situation. The only real problem of justice between different generations stands in the manner the institutions regulate the access to the limited resources in time, in other words, act with advantage given the historical possibilities. It doesn't interest us much the ethical-political side, even though it is relevant, of the already robust speech about the intergenerational justice, but that side understood from Rawls, of the symbolical and virtual feature that each generation establishes with their future, beginning in the present. Continuous intersection of synchrony and diachrony, the generations cannot exist as identity, but as reference - frequently antagonistically - to the dissimilarity (the other "generations"). Thus their identities live from a complicity posture in the comfort of those who distinguish themselves.
\end{abstract}

Keywords: Generation. Justice. Intergenerational. Time. Future.

\section{Sumário}

1 Tempo da Vida e Tempo do Mundo. 2 Transitional Objects. 3 Justiça Intergeracional. 40 que Fizeram os Póstumos por Nós? 50 Tempo das Gerações. 6 Dons e Obrigações Infinitas. 7 A Síndrome de Palomar. 80 Futuro do Direito. 9 Referências 


\section{TEMPO DA VIDA E TEMPO DO MUNDO}

Jogos sutis aqueles que se instauram entre tempo da vida, de "uma”, de "cada" vida, e tempo do mundo, daquele "mundo" que abstrai, sobrepõe, transcende, compreende dentro de si a vida. Remetem a uma espécie de complexidade rival entre as biografias e a história, na qual se amarram os complexos entrelaçamentos do diversificado multiversum e do singular universum. Separam-se e se agrupam, se distanciam e se aproximam, escolhem campos diversos, compartilhando o mesmo espaço. Assim, inesperadamente, desenham percursos sempre diferentes e sempre iguais. Poderemos lê-los na ótica da "justiça", assim como deles poderemos falar, mediante a ótica da "tradição" ou da representação do "tempo". Desta forma, descobriremos sempre que o "nosso tempo", como escreveu Derrida, ${ }^{2}$ é este exato tempo do qual não poderemos tão facilmente falar.

O lugar onde tudo isso se condensa é visivelmente aquele da relação entre um puer um senex de um lado e o das épocas históricas, que oscilam entre um passado e um futuro, de outro. Espaço de experiência e horizonte de expectativas ${ }^{3}$ são as categorias que o pensamento contemporâneo nos sugeriu e as que constituem a ligação sutil entre vida e mundo. Aquilo que para o presente representa o futuro das gerações, as épocas futuras, é o passado e vice-versa; e, no terreno da vida e da biografia, é entrelaçamento entre o puer, que tem expectativa, e o senex que tem experiência. O puer faz, mas não tem experiência, o senex tem experiência, mas não faz uso dela. É importante escavar sobre estes entrelaçamentos.

Quando na linguagem normativa aparecem as "gerações futuras", ocorre aquilo que C. Schmitt, em Amleto o Ecuba (Hamlet ou Écube), ${ }^{4}$ havia descrito como uma singular einbruch, uma invasão do tempo no

2 Derrida, Jacques. Donare il tempo. Milano: Raffaello Cortina, 1996.

3 Koselleck, Reinhart. Futuro passato. Gênova: Marietti, 1986.

4 Schmitt, Carl. Amleto o Ecuba. Bologne: Il Mulino, 1983. 
jogo do drama. Tempo e espaço se dilatam com respeito a um presente ao qual a lei se dirigira por muitos séculos, desde quando abandonara aquele tempo eterno que acompanhava as Constituições. O tempo das gerações futuras, talvez ligado ao imortal jacobinismo, que nenhuma razão iluminística pudera neutralizar, altera o horizonte de referência normativa: o Direito começa a falar em nome de uma presença ausente. A economia de tempo se articula sobre uma dimensão espacial diferente, que não é mais aquela da contemporaneidade; talvez seja ali que comece a se delinear a forma de uma categoria que se manifesta sobre a cena pública, alterando cada equilíbrio, tornando inquieto o panorama dos conceitos rotineiros para depois, talvez justamente por isso, novamente desaparecer e afundar. Esta categoria é aquela da fraternidade, que é o paradigma biopolítico por excelência, com as suas aberturas e as suas desmedidas concretudes, mas também com os paradoxos que carrega e que cria a sua volta. ${ }^{5}$

Ao longo deste percurso refletiremos a respeito de algumas dimensões do tema das gerações futuras, que impõem outros olhares, mas implicam também novas normas.

Sempre que se apresenta o jogo, por definição anacrônico, tempo da vida versus tempo do mundo, seja do ponto de vista da vida ou do ponto de vista do mundo, as incongruências temporais iluminam o tempo das suas próprias observações: mudam com o passar do tempo, permanecendo estáveis. Cada escatologia da vida, e as religiões nos ensinam muito, assim como cada secularização do tempo da vida, deve trabalhar sobre a diferença, que representa um outro tempo, o tempo do mundo; ${ }^{6}$ mas também o tempo do mundo, e as cosmologias mais diversas nos falam a respeito, deve ser observado a partir dela e em relação a sua diferença, que é o tempo da vida. E não basta, porque o tempo da vida não pode ser

5 Resta, Eligio. Il diritto fraterno. 6. ed. Roma-Bari: Laterza, 2006

6 Marramao, Giacomo. Minima temporalia. Milano: Il Saggiatore, 1990. 
observado sem que isto seja feito de dentro do tempo da vida: é envolvente, Umgreifende, e por isso descreve um tempo imaginando um tempo. A sua invisibilidade está na superfície: quando Heráclito no fragmento 52 aproxima o tempo aos jogos infantis, coloca lado a lado a minuciosa medição do tempo da vida e a intemporalidade da brincadeira, remetendo à combinação do jogo de dados, que se dá “ao acaso”, com o tempo indefinido de uma criança: aquele por ela repetido ao pedir "ainda uma vez" uma fábula ou a reiteração de uma brincadeira, aquele que deseja "parar" o tempo. "O tempo é uma criança que joga com dados; de uma criança é o reino" (aion pais esti paizon pesseuon; paidos e basileie). O tempo de uma criança nutre-se do anacronismo da brincadeira, que consiste justamente em interromper o tempo e que, no país do ócio pueril, nos põe próximos, imprevistamente, da eternidade de um calendário medido exclusivamente sobre a festa.

Os mil planos do tempo multiplicam as suas semânticas. O exemplo do estoicismo de Sêneca é eloquente; quanto mais se percebe a brevidade diante da indefinição do tempo do mundo, mais uma vida poderá ser medida pelas gratificações e privações da plenitude de uma jornada; a carta a Lucilio responde à pergunta sobre como Sêneca usa o seu tempo e a resposta é breve. A cada noite passa em resenha a sua jornada: hoje a sua jornada foi completa, inteiramente dividida entre o sono e a leitura, logo não foi privada de nada. ${ }^{7} \mathrm{O}$ tempo de uma jornada pode ser de privações da completeza: fica incompleta quando emprega o tempo em privações do tempo (quando não perde tempo) em afazeres públicos. Não se trata mais da temática que discute a diferença entre tempo público e tempo privado, mas é uma eloquente centralização no duplo código do tempo: a brevidade da vida impõe completude e não privação de tempo. Como é notório, será necessário esperar muitos séculos para que a brevidade da vida invoque

7 Sêneca, Lucius Annaeus. Cartas a Lucílio. [S.1.: s.n.]. 
uma completude diversa, totalmente empenhada em prazeres mundanos, muito diferentes daqueles invocados por Sêneca, assim como será preciso esperar outros tempos e outros lugares, a fim de que justamente esta brevidade seja estímulo para deixar rastros do próprio tempo, que se prolonga e se transmite, de geração em geração, para além do tempo da vida. E é projetado em um tempo de vida mais longo justo porque o tempo de vida é breve. Por outro lado, os antropólogos nos descreveram minuciosamente como os sistemas de parentesco patrilinear ou matrilinear envolvam ideias de tempo diferente, mas nos descreveram também como mudam os sistemas de parentesco em relação à concepção de tempo que um sistema cultural elaborou. E quando um sistema cultural elabora uma concepção de tempo conecta em um único tempo os dois anacronismos: do tempo da vida e do tempo do mundo e o faz nos modos mais diversos que a observação lhe consente e a necessidade de autorregulação lhe impõe. Por isso em alguns sistemas sociais é a descendência parental a proteger a continuidade, enquanto em outros é a transmissão do saber da casta; em alguns é a escrita, em outros é a tradição oral e assim por diante.

Onde a conexão entre o tempo da vida e o tempo do mundo é mais difícil - e a semântica histórica nos dá o testemunho de muitas perspectivas diferentes de tal dificuldade - os paradoxos se deslocam sobre duplas modalidades de percepção da vida e do mundo em chave de "alívio": o imperativo aparece destinado a atenuar e a adequar uma assimetria demasiado exaltada. É mais uma vez o tema da brevidade da vida a coagular as percepções da difícil interconexão dos tempos (da vida e do mundo). Odo Marquand, estudioso (não por acaso) da apologia do acaso, a este respeito deu-nos recentemente uma leitura significativa: ${ }^{8}$ quanto mais a brevidade se impõe como sensor da diferença entre tempo da vida e tempo do mundo, tanto mais se joga paranoicamente sobre diversas velocidades

8 Marquand, Odo. Antropologia del tempo. In: Intersezioni, XV, n. 3, p. 365, 1995. 
que possam completar da maneira mais adequada o descarte. As assimetrias encontram tentativas de neutralização, perseguindo os próprios modelos, capazes de reduzir o descarte e, para Marquand, vale tanto para os sistemas da personalidade quanto para os grandes sistemas funcionais. De resto basta recordar-se como, no debate sobre sistemas econômicos, os modelos binários de desenvolvimento e subdesenvolvimento, uma vez chamados de dualismo econômico (Vera Lutz), eram interpretados como modelos de velocidades diferentes. O desenvolvimento tinha ritmos acelerados, que podiam ser alcançados pelo subdesenvolvimento com uma maior aceleração. Isso pressupunha, entretanto, que a perseguição tivesse sucesso somente quando o metro da velocidade não fosse determinado pelo desenvolvimento, isto é, por um dos adversários do jogo, ou pior, pressupunha que, enquanto o subdesenvolvimento perseguisse, o desenvolvimento, nesse meio-tempo, detivesse a corrida e esperasse. E pressupunha também que os tempos de perseguição não tivessem jamais um fim a partir do qual mensurar: a perseguição nos tempos longuíssimos do mundo se torna também suscetível de sucesso, justo pela indefinição do tempo. Quando, porém, o tempo se apresenta não por meio de prazos indefinidos, mas em termos de insuficiência absoluta, induz a teoremas menos ilusórios e menos seguros; leva a respostas paradoxais, tais como: aumentar a velocidade, adquirir lentidão, misturar velocidade e lentidão. Em qualquer caso oximoros.

\section{TRANSITIONAL OBJECTS}

Este anacronismo nos é sugerido por uma lenta, e muitas vezes silenciosa, desapreciada semântica, feita de linguagens não evidentes, muitas vezes no limite da ingenuidade: coincide com a introdução, no paradigma do tempo presente, de um tempo diferente, intertemporal, que é aquele das gerações futuras. Vem sendo construído há algum tempo; publicamente, e justo a partir do momento em que a aceleração do tempo 
encontrou um veículo muito forte no jogo das revoluções e, paradoxalmente, nos testes que ela tem transmitido às gerações futuras. Na Constituição Francesa de 1793 é possível ler, com um procedimento autoirônico, que cada Constituição depende do próprio tempo, logo é indiferente a respeito dele. Ela pode ser modificada a qualquer momento, mas este tempo, presente, é codificado nessa Constituição. Cada geração tem direito de escolher a própria Constituição e esta, seguramente, é reivindicação de autonomia com relação ao passado, ao absolutismo sem Constituição do Antigo Regime. Isto implica também, no entanto, que a geração presente, que jurou esta Constituição, não tenha nenhum direito de escolher a Constituição em nome e por conta das gerações futuras. As gerações futuras são gerações diferentes, porque os seus tempos serão outros e é por respeito a elas que não se escolhem Constituições para as gerações futuras. Renunciar ao etnocentrismo do tempo de uma geração, em nome de outro, que unifica uma nova geração, é uma operação paradoxal, mas significativa. Existe um tempo no qual as gerações confinam: os seus tempos são iguais e diferentes, se aproximam e se separam, no entanto se interrompe o tempo da tradição e começa o tempo de outra tradição, aquela que diz que cada tempo poderá escolher o seu tempo. A tradição do tempo diz que não existirá somente uma cronologia da tradição do tempo. $\mathrm{O}$ anacronismo se apresenta e a alternativa de se colocar sobre uma linha divisória se abrevia.

Não será o Direito "moderno" a desvelar esta dimensão do tempo, porque a incorporará até o fim, estabelecendo indiferença com relação ao tempo, escondendo-a nos dispositivos da sua Positivierung. Será ao invés a ética, justo aquela que havia experimentado todos os jogos das cronologias e dirigido o próprio olhar interessado à brevidade, ao término, à atualidade do presente (e justo graças às diversas colorações da sua teoria) a elaborar até o final aquele particular anacronismo do futuro do presente: ética para as gerações futuras é um produto deste presente. A sua semântica é aqui, na contemporaneidade mais visível. É levada a recair numa 
hermenêutica, entendida como mecanismo de comunicação, na qual tudo depende mais uma vez da tra-dizione, do modo de passar e de transmitir, ou seja, tradere. Vale para as gerações o código da familiaridade: Winnicott recorda-nos de que uma criança, quando é conduzida a lugares não imediatamente familiares, estabelece continuidade com a própria dimensão cotidiana, levando consigo objetos, como o famoso ursinho de pelúcia. A mudança de gerações vive desta mesma transitoriedade, mesmo quando afirma tomar distância dela.

O seu quadro de referência não é neutro, mas, ao contrário, nítido e eloquente. Quanto mais avança a velocidade do prometeico, do qual este tempo se apropria, e quanto mais incontrolável se torna o seu dispositivo, mais é preciso duplicar-se e assumir por si anacronismos capazes de colocar em jogo tempos distintos. A velocidade incontrolável se aprisiona no tempo da técnica "desenfreada": a sua representação torna-se aquela do Prometeu "incontido", quase um escravo liberto de suas correntes e que, finalmente desvinculado dos pesos que o prendiam, acaba por assumir o papel do patrão que o mantinha escravo. A irresponsabilidade da técnica alcança um mimetismo sem par com relação ao seu velho mítico patrão, que o tinha mantido acorrentado: e o que vem a ser o mito prometeico, se não o mecanismo da diferença entre a irresponsabilidade dos deuses e a responsabilidade dos homens e de uns em relação aos outros? Somente o mundo dos deuses, recorda Benjamin, é o mundo em que não existe lugar para a infelicidade e a culpa (per differentiam). A velocidade da técnica responde somente ao tempo do seu desempenho: o seu código é aquele de poder fazer tudo aquilo que se pode fazer. Tudo o que a técnica pode fazer, porque é em grau de fazê-lo, o pode fazer. Responde somente a si mesma em monólogo e de maneira tirânica, porque $a b$-soluta, livre da obrigação de responder sobre qualquer coisa a ninguém mais do que a si mesma. $\mathrm{O}$ seu tempo é veloz e desenfreado porque não deve parar para responder nada a ninguém mais do que a si mesma: não perde tempo, então não pode deter-se sobre sutilezas que a obstaculizam. Não considera nada nem 
ninguém, porque considerar leva à reiteração dos olhares, que desconcentram e distraem da meta. As considerações implicam um mínimo de autoobservação dialogada, que desvia dos monólogos. A técnica e seus tempos não podem dialogar com nada e com ninguém e o fazem também quando dizem de fazê-lo para todos e para todos os tempos. Tanto o modelo da cumulatividade das descobertas cientificas, quanto aquele per-formativo, que diz que a última descoberta fala em nome da verdade, porque é mais "moderna”, têm uma lógica de tempo unilinear, absoluto: representam a "malvada eternidade" da qual falara Cioran. ${ }^{9}$

A interrupção deste tempo monologante concentra-se em uma pequena dúvida, que se insinua e se separa do tempo linear e do tempo dividido simetricamente em duas partes; assume o caráter de uma hesitação incerta e "meditativa” (à qual retornaremos), consignada exclusivamente a um sinal interrogativo de interpontuação. O tempo se interrompe quando alguma outra linguagem transforma o monólogo do "podemos fazer tudo aquilo que podemos fazer" em pergunta, que procura a sua resposta e por isso evidencia novamente a necessidade de responder a alguém a respeito daquilo que "podemos fazer" porque a estamos fazendo: a pergunta se torna "podemos fazer tudo aquilo que podemos fazer?" A velocidade do tempo se esfacela simplesmente na interrogação, em um tempo que hesita e se pergunta; perde tempo e faz perder tempo, se impõe considerações. E o tempo da pergunta que hesita é o mesmo tempo da velocidade desenfreada do "sem resposta", do não responder. No mesmo mundo e na mesma sociedade o tempo da técnica convive com outro tempo, que impõe a perda de tempo, porque invoca respostas e responsabilidade. $\mathrm{O}$ estilo dialogal tem tempos diferentes daqueles do monólogo, aguarda interlocutores e se desenrola no tempo duplo de fazer perguntas e “esperar” respostas, se alonga e é medido sobre diversos tempos que o

9 Cioran, E. M. La caduta nel tempo. Milano: Adelphi, 1995. 
monólogo, sem resposta, não requisita. Tempos diversos, que convivem até que o anacronismo seja de tal maneira estridente, a não poder dar-se conta disso porque, quanto mais os tempos conflitam sobre as diferentes medidas a serem dadas à convivência, tanto mais o dissídio pede "terceiras” medidas, ou pior, coloca em evidência estratégias capazes de circundar o impacto (differend).

É obviamente significativo que tenha sido a ética a introduzir a interrupção do monólogo da técnica e a requerer tempos diversos e isto nos impõe refletir como se "comunicam" no interior de um mesmo tempo, feito de tempos diferentes: nos impõe refletir "ecologicamente" e impõe ao sistema auto-observações (não importa com quais êxitos, mesmo que seguramente paradoxais, como o debate sobre a ecologia nos ensina). $\mathrm{Na}$ ecologia da comunicação pode-se dizer que a ética, talvez porque mais habituada aos anacronismos, condensou a pergunta sobre a responsabilidade do tempo da técnica e produziu uma medida diferente do seu tempo e o fez recentemente, interrogando-se sobre o "princípio responsabilidade". ${ }^{10}$ São dois os elementos anacrônicos sobre os quais devemos nos deter, perdendo obviamente tempo: o primeiro é aquele derivado da angústia de uma velocidade incontrolável, que impõe parar e refletir (heurística do medo), o segundo é o anacronismo, por meio do qual, no horizonte deste tempo presente, se insere outro tempo, aquele das gerações futuras.

Uma singular iniquidade acompanha a ideia de tempo no qual indivíduos, grupos ou povos vivem. Essa é implícita em um silencioso mecanismo de dependência entre aqueles que virão e aqueles que já vieram. Mais ou menos conscientemente, aqueles que vivem no tempo presente têm o poder de fazer alguma coisa, no bem e no mal, por aqueles que os seguirão. Não sabemos nem mesmo com segurança se seja bom ou ruim fazer alguma coisa; racionalmente podemos pressupor que os "póstumos"

${ }^{10}$ Jonas, Hans. Il principio Responsabilità. Torino: Einaudi, 1991. 
dependam dos "presentes”, sem por isto conceder qualquer supervalorização ao papel destes últimos. Existirá talvez nisto um mínimo de postura de “onipotência”, mas é razoável pensar desse modo.

A relação entre os presentes e os que virão depois dele, é uma espécie de estrada de mão única, na qual a direção da escolha passa dos presentes aos póstumos.

J. Rawls, em 1971, em um período no qual a crise do welfare não era certamente sentida e estas temáticas faziam parte de uma geração de filósofos vindos da Segunda Guerra e das suas destruições, em Una teoria della giustizia, explica tudo isto com extrema incisividade:

É um fato natural que as gerações estejam situadas no tempo e que as efetivas trocas entre elas aconteçam somente em uma direção. Nós podemos fazer alguma coisa para os póstumos, mas eles não podem fazer nada por nós. A situação não pode ser mudada e, por este motivo, não se coloca nenhuma questão de justiça. O que é justo ou injusto é o modo no qual as instituições tratam os limites naturais e o modo como estas são estruturadas a fim de tirar vantagem das possibilidades históricas. ${ }^{11}$

\section{JUSTIÇA INTERGERACIONAL}

Não se pode saltar o jogo das gerações; ele é inscrito dentro de vínculos naturais que não podem ser desfeitos. Logo, a indiferença é justificada pela imprescritibilidade que não pode mudar conhecimento e situação. $\mathrm{O}$ único problema verdadeiro de justiça entre gerações diferentes coloca-se pela maneira na qual as instituições regulam o acesso aos recursos limitados no tempo, ou seja, agem com a vantagem dada pelas possibilidades históricas. As trocas efetivas então existem, observa

${ }^{11}$ Rawls, John. Una teoria della giustizia. Milano: Feltrinelli, 1982. p. 249. 
Rawls, ${ }^{12}$ mas são “virtuais"; são sempre mediadas por um presente que se auto-observa e se autorregula, em uma possível e vinculada relação com o seu futuro.

Não nos interessa tanto a vertente ético-política, mesmo sendo relevante, do já robusto discurso sobre a justiça intergeracional, mas sim aquela entendida a partir de Rawls, do caráter simbólico e virtual que cada geração instaura com o seu futuro, partindo do presente.

Creio que este seja um tema importante: ele envolve modalidade de observação, de descrição e de regularização de si mesmo que o sistema social propõe e que me parece de grande interesse para entender se pode mudar, e de que maneira, aquela que, com um termo equívoco e arriscado, se chama a mentalidade coletiva de uma época.

As gerações, as suas relações virtuais, os seus jogos, não são nada além do que aquele mundo de símbolos dos quais é exclusivamente constituída a sociedade, como nos recorda Hugo von Hoffmanstahl no Libro degli amici. ${ }^{13}$

É um tema complicado aquele das gerações, repleto de paradoxos: vivem de um tempo que é por definição instável, mas se representam com identidades estáveis. Quanto mais provisórias, tanto mais se inclinam a se construir como algo que não se altera, como a estrutura imutável de uma história.

Cruzamento contínuo de sincronia e diacronia, as gerações não podem existir como identidade, senão como referência - frequentemente antagônica - à dessemelhança (as outras "gerações”). Assim as suas identidades vivem de uma postura cúmplice no confronto daqueles dos quais se distinguem. Sempre sobre o vau de duas margens: o indivíduo e a

\footnotetext{
${ }^{12}$ Ibidem.

${ }^{13}$ Hoffmanstahl, Hugo von. Libro degli amici. Milano: Adelphi, 1980.
} 
comunidade. De fato não raramente o termo "geração" se faz acompanhar de um possessivo: a minha, a nossa geração. Às vezes conota "pertinências" históricas (a geração depois da guerra, aquela de 68); outras vezes limita-se a indicar cronografia ou meras sucessões temporais (a segunda geração de imigrantes, a cibernética da terceira geração). A geração classifica alguma coisa, definindo-a e isolando-a de alguma outra coisa; identifica, mas sobre uma base de contínua provisoriedade.

Termo ambíguo "geração"; estabelece de qualquer maneira e sempre relaciona a partir de um tempo e de uma identidade que não vivem, senão referidos um ao outro. Outro fator de uma geração é a existência de um dispositivo, através do qual observamos e somos observados por nós mesmos...

Ainda Rawls, mas ele depois de tantos outros, retoma o tema da justiça intergeracional no seu último Political Liberalism corrigindo e pontuando algumas asserções precedentes. Uma em particular merece ser sublinhada: "A sociedade é um sistema de cooperação através das gerações e das épocas”. ${ }^{14}$

Justo Rawls, que tinha considerado as gerações como "destinadas" a um vínculo direcional e imutável, põe no centro da ética a questão das gerações, até definir a sociedade como um "sistema” (mas o uso talvez seja um pouco genérico) de cooperação entre gerações.

Cooperação quer dizer ligação estável, ainda que virtual, em função de uma tarefa comum. As gerações que cooperam não estão em sucessão histórica imediata, menos ainda em condição de coexistência (pais, avós, filhos). Elas estão distantes no passado e no futuro: desta algumas são, até mesmo somente possíveis, porque dependem de escolhas imediatas que o presente adotará a respeito do próprio futuro. Alguns indivíduos

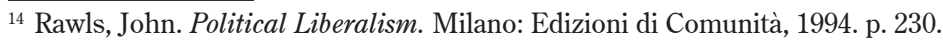


de gerações futuras ou algumas espécies futuras poderão não existir ou serão diferentes de como o presente pode imaginá-las, mas a relação que se instaura com o futuro, a partir do presente, não pode ser eliminada.

Na ideia de cooperação existe uma forma particular de ética pública, contratualista, no caso de Rawls, mas existe também uma ideia de sociedade construída sobre o jogo perene e indestrutível das gerações. As espécies biológicas, se sabe, podem mudar e até mesmo perecer, mas o sistema social não, até quando se possa comunicar por meio da sucessão e da metamorfose das espécies, inclusive a humana. As gerações assumem então o caráter daquele tecido simbólico e comunicativo com o qual um sistema social observa e descreve a si mesmo: dele constituem a linguagem.

As definições não são somente utensílios mais ou menos refinados para organizar saberes. Frequentemente são por sua vez traços eloquentes de como os sistemas teóricos observam a sociedade. Quem segue na curva dos últimos decênios as numerosas definições de "sociedade", verá que aquelas mais difundidas falam dela como de um sistema de cooperação; outras, ao contrário, como de um sistema de conflito. A única variante de consistência insegura é representada por definições da sociedade como “jogo de cooperação" contra "jogo de conflitos”. As teorias mais complexas e mais elaboradas, ou somente mais prudentes, falam de sistemas ou de jogos mistos de cooperação e de conflito, imaginando-os como em um mecanismo que pode ser medido gradualmente, de um máximo de conflito, a um máximo de cooperação. Ou seja, descobrem a relação e a dependência recíproca de termos como "cooperação" e “conflito", que não podem ser observados senão um em referência ao outro.

As dificuldades depois se reencontram no classificar épocas concretas ou simples teorias como mais ou menos cooperativas ou mais ou menos conflituosas. E os exemplos são divertidos: quando é necessário 
dar um lugar a Marx, que parte do conflito para chegar a sua pacificação, ou a Pareto e Parsons, que falam continuamente de tendências instáveis ao equilíbrio, a teoria deve reajustar continuamente a si mesma.

Logo, cooperação e conflito são estruturas do sistema social de tal forma consolidadas que é possível construir uma definição sobre elas, mas referem-se sempre a um concreto sistema social ou a um sistema teórico fixo e parado em um dado momento.

Quando Rawls ${ }^{15}$ define a sociedade como sistema de cooperação (conflitual ou de conflitos cooperativos) entre gerações e épocas, introduz um elemento inovador. Indica que o modo de pensar a sociedade está se movimentando. Está se alargando o horizonte da experiência do sistema social para um tempo que coloca em discussão o absolutismo do presente. A ética, deste ponto de vista, tematiza problemas que já foram sugeridos no sistema social que, como vimos, percebe rejeitos entre diversas dimensões de tempo e tematiza as suas percepções sob forma de anacronismos. Sem diminuir-lhe a importância, mas analisando somente sob a ótica de uma perspectiva de incongruência, a ética informa justamente mediante suas tematizações um modo de observar e de descrever e, sugerindo formas possíveis de regulação, mostra como problemas de regulação do tempo vêm sendo enfrentados "dentro da sociedade" e a partir do próprio sistema social.

O que é posto em discussão, todavia, é o fundamento da troca intergeracional e, por este motivo, a justiça entre gerações. A tradicional estrutura contratualista, tanto na versão hobbesiana quanto na lockiana, pressupõe reciprocidade, a qual, no caso das gerações futuras, é difícil conjeturar. Seria necessário recorrer a um modelo contratual dissimétrico, ausente de reciprocidade e, sobretudo diacrônico: a solução é obviamente problemática e se reflete na qualificação da relação “jurídica” entre gera-

${ }^{15}$ Rawls, J. Una teoria della giustizia. Milano: Feltrinelli, 1982. 
ções presentes e gerações futuras. Escolher entre os direitos das gerações futuras e os deveres das gerações presentes não é uma operação mecânica de escolha entre equivalentes funcionais.

\section{O QUE FIZERAM OS PÓSTUMOS POR NÓS?}

O ato de olhar as gerações esconde uma "gramática do ver" totalmente construída sobre aquilo que o observador percebe dentro do seu horizonte de tempo e de espaço, não fugindo, então, dos paradoxos do presente.

Isto me parece que deva ser levado a sério e sobre estas observações paradoxais necessita investigar, e os problemas da ética, em uma perspective by incongruity, nos dizem muitas coisas sobre nossos paradoxos. Informam-nos, assim, dos limites do presente, por meio da ética do futuro, nos sugerem que não podemos fazer tudo o que podemos fazer, lembram-nos de que o nosso espaço e o nosso tempo de vida não são únicos e nem absolutos; expandem a ideia do nosso "próximo"; complicam o conteúdo das nossas decisões imediatas e cotidianas, mas enquanto nos fazem ampliar o olhar sobre o futuro, lembram-nos ambiguamente de que a única vida que podemos viver é no presente, exatamente como no próprio presente viverá cada uma das outras gerações. Em uma palavra, nos habituam a nos auto-observar quanto mais nos sugerem observar o "futuro".

A ética, porém, nos faz ver que, a partir da esfera do pequeno e do individual, as gerações se tornaram o nó das escolhas coletivas sempre maiores e sempre mais comuns e de todos (do micro ao macro). Assim como no século 17 a teoria sugeria o problema da ordem social, tematizando a desordem da guerra, hoje a insistência sobre as futuras gerações nos remete, com certa urgência, ao drama do presente. 
O nexo entre aquelas observações e estas, entre aquela elaboração do tempo e esta, é menos contingente do quanto não pareça; ambas trabalham sob uma heurística do medo, ${ }^{16}$ que empurra em direção ao anacronismo do presente e ajuda a tematizar observações e regulações do sistema social. Às origens da modernidade metus et indigentia exigiam a liquidação de um passado de violência indiferenciada e investiam no soberano para ter um presente calculável, no qual critérios de responsabilidade entre os cidadãos fossem recíprocos e simétricos; a necessitas empurrava em direção à definição dos espaços próprios, em razão dos espaços do outro, em base a convenções das quais o soberano deveria ser garantidor. $\mathrm{O}$ tempo era o presente e o próximo era tão próximo a ponto de ser concorrente.

No final da modernidade um medo mais sutil e a ausência, ou impotência de um soberano, leva a uma nova regulação da sociedade, na qual os indivíduos são deixados sozinhos defronte de um próximo espacial e temporalmente mais amplo. As responsabilidades são as próprias, mas o sujeito ao qual se deve responder são as gerações futuras; na ausência de um soberano, de um terceiro que possa imputar responsabilidade, esta se reflete nua sobre o presente, sobre o contemporâneo. A tragédia moderna reside justamente em descobrir-se sendo chamado, e ter de responder a tudo, sem poder ser responsável por isto. A imagem que pode representar este caráter trágico é Vor dem Gesetz, de Kafka, ${ }^{17}$ na qual a responsabilidade nos impõe perguntas sobre toda a realidade que nos circunda e que é feita de tempos que nem sempre nos pertencem e pelos quais somos chamados a responder, sem poder fazê-lo.

\footnotetext{
${ }^{16}$ Jonas, H. Op. cit.

${ }^{17}$ Kafka, Franz. O processo. [S.1.: s.n.].
} 
A ideia de desencantamento, da qual o pensamento ocidental se nutriu e que frequentemente considerou um pressuposto da própria racionalidade, não economizou a própria concepção de tempo.

Até mesmo, se não principalmente, quando se apresentava sob as vestes otimistas de um progresso evolucionista indiscutível. Até mesmo quando, dizia Wittgenstein, ${ }^{18}, 0$ "progresso” tornava-se não uma característica ou uma qualidade, mas a própria estrutura da sua história.

Basta para isto tornar a percorrer as páginas dos Scritti politici (Escritos Políticos) de Kant, ${ }^{19}$ que na Idea per una storia universale (Ideia para uma História Universal) rechaçava a possibilidade, porém teórica, de que as gerações precedentes devessem carregar o peso pelas sucessivas e de que a gozar de todas as vantagens disto devessem ser as últimas. Nada que fizesse parte da moral racional e nenhum princípio, nem mesmo utilitário, teria podido justificar "sacrifícios" de uma geração pelas sucessivas.

Sobre este tema cada teoria da justiça intergeracional não pode não retornar; J. Rawls recorda a teoria da iniquidade cronológica descrita por Herzen, segundo a qual o desenvolvimento humano seria caracterizado por uma injustiça de fundo, mediante a qual as gerações presentes tirariam proveito do trabalho das gerações passadas sem pagar o menor preço. As gerações sucessivas seriam então, o protótipo dos free riders, dos aproveitadores. É possível obviamente inverter o argumento sobre a base da mesma ideia evolucionista do desenvolvimento, porque se o desenvolvimento é constante, se tira proveito do passado, mas ao mesmo tempo se trabalha para o futuro. É interessante, porém, como Herzen e

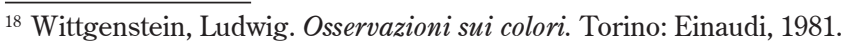

${ }^{19}$ Kant, Immanuel. Idea di una storia universale dal punto di vista cosmopolitic. In: Scritti politici e di filosofia della storia e del diritto. Torino: Utet, 1956. 
Kant omitem dos seus campos de observação o tempo da reciprocidade que uma ideia de desenvolvimento tinha podido sugerir; de outra parte é justamente com Kant que ganha corpo o conhecimento da atualidade.

Se os povos ameríndios são excessivamente presbíopes, esta leitura ocidental é míope demais. Ou olha perto demais o presente, porque não pode ou não quer alongar o olhar para o futuro, ou limita a "diacronia" ao passado. Desenvolve-a em sentido único e, no caso de Herzen, a constrói de acordo com o modelo do olho da rã, que pode perceber fotogramas, mas não sequências. E, obviamente, o olhar cai e aponta para o presente, anulando - ou omitindo - o futuro.

“O que fizeram os póstumos por mim?” recita uma irônica piada de Woody Allen, que nos recorda com outro estilo e outra linguagem o inteiro problema, sobre o qual se aflige a teoria distributiva da justiça intergeracional. É justamente em torno desta pergunta que se articulam as leituras da equidade entre as gerações que, da troca de recursos, deslizam na direção de éticas e práticas da identidade. Elias Canetti, ${ }^{20}$ não por acaso, pensa nas gerações futuras (e nas passadas) como "massas invisíveis”, que adquirem a característica da "densidade” através do tempo, assegurada por números elevados, por sequências ininterruptas e unidades, até quase a ausência de diferenciação.

\section{O TEMPO DAS GERAÇÕES}

Tanto a falta de confiança em direção ao futuro quanto o foco no presente provocam enriquecimentos analíticos sem dúvida salutares e não apenas para o aperfeiçoamento da arte da argumentação, mas para a própria compreensão de uma teoria da História.

${ }^{20}$ Canetti, Elias. Massa e potere. Milano: Adelphi, 1981. p. 55. 
Quando J. P. Sartre, nos Cahiers pour une morale, ${ }^{21}$ reflete sobre o conceito de "gerações históricas", o seu ceticismo se serve de argumentos insistentes, que partem de um exórdio significativo derivado de Dilthey: “84 gerações, afirma Dilthey, depois da república romana”. A suspeita a respeito de uma história medida sobre as gerações esconde a falta de confiança na sua continuidade. Assim, a crítica de Sartre aponta sobre os usos linguísticos e sobre os significados atribuídos ao conceito de "gerações". A sua desconfiança é exata: o problema é aquele de definir o que é uma geração. É uma causa histórica, uma modalidade do desenvolvimento, um lugar para transferir à posteridade, o veículo de uma tradição, um critério de medida de um tempo mais ou menos artificial, um fator ontológico? E qual é o espaço de tempo que separa uma geração da outra?

Poderiam ser 25 anos, dada a diferença de idade entre pai e filho na Europa, mas o argumento não é bastante universal. Pode-se então falar de geração somente por convenção; como exemplo pode-se identificar uma geração do pós-guerra, mas neste caso o tempo é decomposto a partir do evento da guerra, que regula a idade, e a confusão entre denotação e conotação é excessivamente alta. A desconfiança de Sartre refere-se ao caráter abusivamente problemático e ideológico do conceito de geração, que recoloca uma "decisão" demasiadamente imersa na "biografia” e na reconstrução que o presente impõe ao passado. Onde filosofias da história são fortes demais e muito rigidamente construídas sobre macrovariáveis, a ideia de gerações ou é episódica ou é completamente irrelevante. Isto vale para cada Filosofia da história, do marxismo ao existencialismo.

Esta é a maior razão para indivíduos que compartilham de uma instabilidade histórica bastante elevada e nos quais, em diferentes medidas, é forte a disponibilidade à mudança; até mesmo à mudança da própria

${ }^{21}$ Sartre, J.-P. Quaderni per una morale. Roma: Edizioni Associate, 1991. 
biografia. ${ }^{22} \mathrm{O}$ raciocinar em termos de gerações expõe uma contingência excessivamente provisória e seletiva, pode-se falar deste tema, mas somente na linguagem do senso comum. A identificação de gerações e de épocas escorregaria no acaso e no arbítrio. Seria um terreno demasiadamente incerto para aventurar-se e, se o passado é problemático, imagine-se o futuro!

"É claro, conclui Sartre, que a distinção em gerações não pode servir para explicar o conteúdo do fato histórico"; pode servir como descrição formal da sua estrutura ontológica. O código da linguagem muda de geração a geração. É evento, é fato para a geração futura, projeto para aquela passada.

A expressão “épocas geracionais" indica as épocas, isto é: as fraturas, as divisões e não as gerações. O movimento das gerações reproduz o mecanismo de um carrossel, sobre o qual o observador subiu.

A única operação que este observador pode-se consentir é aquela de "temporalizar" o tempo: não mais observar do carrossel em movimento, mas descer dele e observá-lo em movimento, com um notável e admirável exercício analítico. Pode observar aquilo que para as gerações passadas se entendia como o próprio futuro.

Cada geração se torna o resultado de um Vergangene Zukunft, de um futuro passado, ${ }^{23}$ em que é possível reencontrar precisamente tudo, da volta do sempre igual, ao movimento incessante, até mesmo a aceleração do tempo histórico, que confraterniza jacobinos, revolucionários e manipuladores da natureza.

${ }^{22}$ Berger, P.; Berger, B.; Kellner, H. The Homeless Mind: Modernization and Consciousness, New York: Random House, 1973.

${ }^{23}$ Koselleck, R. Op. cit. 
Assim o relativismo, apesar de salutar, fecha-se na observação de uma história na qual o ponto de chegada das gerações futuras é sempre um presente, mas fechado em seu tempo sincrônico, atual. O que uma geração poderá ver é aquilo que já viu ou o que outras gerações passadas imaginaram como sendo seu futuro. Não podemos ver aquilo que não podemos ver é, por uma vez, a vantagem de uma tautologia.

\section{DONS E OBRIGAÇÕES INFINITAS}

Até mesmo o olhar mais crítico, capaz de decompor cada Filosofia da história, quando afunda sob o anacronismo do tempo das gerações, se limita a um movimento monodirecional, que olha o presente na direção do próprio passado. $\mathrm{O}$ faz com a costumeira perspicácia, mas não pula esse movimento. A troca geracional representa a iniquidade da História e o tempo que a contém cheira a "doença”. Na segunda dissertação de Genealogia della morale ${ }^{24}$ (Genealogia da moral) Nietzsche não deixa de lançar este seu segundo olhar sobre as gerações e inclui o jogo das trocas na moldura não irrelevante da "culpa, da malvada consciência e similares".

A relação entre contemporâneos e progenitores tem pouco a ver com a consciência moral e muito, ao contrário, com uma economia política de trocas, representada na forma de obrigação jurídica. A relação entre as gerações presentes e as passadas, entre os contemporâneos e os seus progenitores, é genealogicamente fundada sobre uma obrigação que liga o devedor ao seu credor: os vínculos sentimentais e as “venerações” não são mais do que o mascaramento do débito. Os contemporâneos reconhecem a própria obrigação no confronto dos progenitores, em vez de mostrar reconhecimento pela "geração", em outras palavras, por serem aqueles os fundadores da estirpe. Mais adiante veremos o quanto é relevante a ideia

${ }^{24}$ Nietzsche, Friedrich. Genealogia della morale. Milano: Adelphi, 1989. p. 78. 
de "débito infinito" e quanto justo a partir de Nietzsche se venha desenredando o fio que liga conhecimento, reconhecimento e gratidão. A dimensão do dom e da obrigação de gratidão no confronto da "gratuidade", mesmo próxima e participando da mesma origem, se diferencia do terreno da obrigatoriedade da troca e ambos, reconhecimento e gratidão, têm uma relação não linear, e até mesmo ambígua, com os mecanismos cognitivos do "conhecimento".

No âmbito da originária comunidade das estirpes, a geração existente reconhece cada vez uma obrigação jurídica no confronto das gerações precedentes, dominada pela persuasão mítico-religiosa de que a própria geração (a "espécie”) existe, graças aos sacrifícios e às obras, se não à "vontade”, dos antepassados. Estes então devem ser recompensados com outros tantos sacrifícios e obras. Vem reconhecida uma dívida que jamais é paga de uma vez por todas, e que ao invés de se extinguir, renova-se continuamente, pelo fato de que cada vantagem sucessiva que aos contemporâneos possa acontecer, recria a obrigação no confronto dos progenitores. A ligação é indissolúvel, linear e em sentido único: tudo deriva de uma "geração”, de um dom de gerar, que vincula obrigatoriamente a restituições infinitas. Gira-se totalmente de ponta cabeça uma ideia de redenção, de rede emere, de recomprar, de retomar no presente aquilo que foi retirado e do qual se foi privado no início, mas nisto se confirma o quadro da troca econômica. $\mathrm{O}$ olhar direcionado unicamente à origem é fixo, não suporta as distrações que o vínculo obrigatório confirma. As novas vantagens que cada geração contemporânea obtém, recriam automaticamente novos débitos diante das gerações passadas de progenitores. Não existe nenhuma gratuidade e onde "gerar" viesse representado como "dom" se trataria de um presente envenenado: a "ambiguidade" da gratuidade se desvelaria de maneira inequívoca. Não existe nenhuma gratuidade; a troca é férrea e as suas leis requerem obrigatoriamente que o synallagma venha honrado. O que se deve dar em troca? Nietzsche é determinado: sacrifícios, festas, mausoléus, atos de homenagem, imposição de grandes condições 
a serem pagas em grupo, sob a forma monstruosa de ritos sacrificais do primogênito, mas acima de tudo obediência: a economia política das trocas geracionais é clara, geração versus obediência. Vínculos rígidos que não podem ser desfeitos e que se renovam quanto mais aumenta a autonomia dos tempos geracionais; quanto mais se arrisca de atenuar o vínculo, tanto mais ele deve ser reforçado. $\mathrm{O}$ débito será infinito e se reforçará com o sagrado desvelado de temor por aquilo que consegue com a traição da estirpe e pelo que a sua potência pode ameaçar ("talvez aqui se originem os deuses, ou seja, uma origem a partir do temor"). ${ }^{25} \mathrm{O}$ vínculo aumenta quanto mais aumenta a duração e a potência da estirpe e vice-versa. Aquilo que é mais difícil de explicar, porém, é o caminho inverso: a despotencialização do vínculo que acontece porque declina a estirpe (e vice-versa). $\mathrm{O}$ ingentilimento degli dei (os deuses que se tornam gentis), assim o chama, acontece a partir de uma época e de um processo no qual na geração se manifesta menos a raiz de temor com relação ao passado. Este se interrompe quando se decompõe a relação unívoca, que do passado vem ao presente, e que força as gerações contemporâneas a renovar o débito no confronto dos progenitores. Os deuses que se tornam gentis fazem com que se perceba menos o sentido de uma troca econômica e jurídica entre as gerações. Ele se encontrará sem raízes e sem obrigações, senão para consigo mesmo: as potências da abstração que o "socratismo" moderno praticará revelarão as gerações como exclusivamente presentes. Também as gerações se tornarão abstratas: o que será então a igualdade abstrata dos códigos modernos, senão a negação de uma obrigação no confronto da origem, mas também a negação de um “dom” que vem do passado?

A abstração do moderno revela este processo e ajuda a entender a emancipação que dele resulta, mas não deixa de advertir que o débito permanece, enquanto o devedor parece ter desaparecido. Sentimo-nos

${ }^{25}$ Nietzsche, F., op. cit., p. 79. 
obrigados no confronto daqueles “deuses tornados gentis”, que não ameaçam e não geram mais temor, mas que nem por isso são credores menos ávidos.

A utilidade da História, que consente falar do futuro de um passado, converte-se rapidamente em dano, consistente e irreparável. A inquietude começa a agitar a sabedoria e o distanciamento do observador, lhe insinua alguma suspeita e o empurra furtivamente a ousar mais com o olhar.

As distâncias que nos separam dos objetos distantes podem reduzir-se, assim como podem reduzir-se decididamente os enormes espaços de tempo que separam épocas e milênios e confinam gerações em mundos totalmente estranhos e não comunicáveis.

As “84 gerações” de Dilthey se dividem à metade drasticamente e o tempo se reduz somente aperfeiçoando o olhar. O que é esse longo tempo que nos separa do mundo antigo? - pergunta-se Nietzsche no seu Utilità e danno della storia per la vita, em que consistem estes dois milênios, a partir daquele ano em que começamos a medir os nossos anos? O que é então este tempo longíssimo que separamos em antigo, pré-moderno, moderno, no qual cada época é um pós de alguma coisa?26

A resposta de Nietzsche é significativa: são 34 vidas, colocadas uma ao lado da outra, considerando uma duração média da vida entre 60 e 65 anos. A ideia de que 34 vidas separem Nietzsche de Tibério reduz enormemente as distâncias; não acelera, mas abrevia o tempo. Torna tudo menor e familiar, menos estranho. Assim o futuro de uma geração está ali, a um passo de distância de uma ou duas vidas. Aproxima-nos do passado, mas faz também com que sintamos mais contíguo o futuro: e a proximidade e a contiguidade fazem aumentar contatos, tornam os espaços comuns, uniformizam vidas e crenças, expandem os confins do amor próprio. Efeito não

${ }^{26}$ Nietzsche, F. Dell'utilità e il danno della storia per la vita. Milano: Adelphi, 1981. p. 66. 
irrelevante de uma involuntária arrogância do gênero humano sustenta Nietzsche, contudo é algo tenaz e perseverante; não quer ser observado nos seus passos - para frente e para trás - com base em milhares de anos, mas ama decompor-se e apresentar-se como sucessão de poucas vidas. A medida trai o vício do observador que, dentro da História, vê a si mesmo na última geração da História e assim o envelhecimento do gênero humano se transforma na sua modernidade. Os milhares de anos são um pedaço breve da História, percebidos do ponto de vista do "tempo do mundo", mas eles são um pedaço longo e distante nas origens, se percebidos do ponto de vista do tempo da vida. E a vida é aquela que, ao lado de outras vidas precedentes, pode perder a profundidade histórica, mas adquirir uma proximidade inesperada.

O observador tira vantagem da própria inquietação; dá-se conta de que pode direcionar o olhar mais além do que está habituado a pensar.

O "segundo olhar", que faltava aos moralistas do seu tempo, Nietzsche o exercita decompondo espaços e tempos habituais já condenados a não indicar nada além da obviedade. O segundo olhar infringe "medidas", decompõe técnicas e deforma instrumentos rígidos demais.

Sugestão bem acolhida por Borges, das Finzioni ${ }^{27}$ (falsidades), que imagina exatamente metros deformados: substituir o sistema decimal de medidas, por outro tão artificial quanto o tri decimal. Assim hoje não mais estamos no ano de 1996, mas em torno de 1500 e eu acabo de superar os 30. Por que um artifício e não o outro? O tempo se contrai e a distância se dispersa, renunciando a sua solidez.

$\mathrm{O}$ artifício, porém, esconde outros tesouros. Quando Borges se curva sob o pensamento medieval, encontra a antiga questão da onipotência de Deus ainda não carregada, no sentido de complicada, das querelas reformistas da graça e da predestinação. O modelo transmitido é aquele do

${ }^{27}$ Borges, J. L. Finzioni. Torino: Einaudi, 1995. 
Deus que governa o destino dos homens. Enquanto, porém, a capacidade de alterar o futuro é também dos homens, como pouco mais tarde ensinará o modelo humanístico do quisquer faber fortunae suae, a ser confiada exclusivamente à onipotência de Deus é, ao contrário, a capacidade de mudar o passado. A humanidade poderia despertar-se um dia com outra história, com outro passado.

A verdadeira onipotência de Deus estaria ali, na capacidade de transformar o passado e não simplesmente na possibilidade de mudar o futuro, o que permanece uma atividade "humana demais". A humanidade então teria outra História, mas também a História teria outra humanidade. É aqui que se inverte uma longa tradição, que de Mateus a Agostino tinha quase exonerado o homem da responsabilidade moral em relação ao futuro; tinha aliviado o seu peso, assegurando-lhe a ideia de Providência. Alívio que, sob formas diversas, se reencontra na mão invisível de A. Smith e na ideia de arcanum, que o desenho imprescrutável da natureza conserva em Kant.

O olho paradoxal infringe certezas: o futuro é projetável e à altura da mão. O incomensurável, o indistinto e, consequentemente, também o imodificável, está no passado. Aquilo que não podemos ver do destino não se deve à impenetrabilidade do futuro, mas às ligações intrincadas do passado.

O verdadeiro nó Górdio a ser cortado (e a ser decidido) está no passado; e nunca, como neste caso, representa o sentimento de uma comum pertinência dos termos alemães Geschichte (história), Schichtung (estratificação) e Geschick (destino).

\section{A SÍNDROME DE PALOMAR}

Vista de dentro, a oscilação da identidade segue os mesmos percursos, mas muda os códigos de referência. A identidade que observa do seu interior, enquanto é observada do seu exterior, assemelha-se a todos 
os observing systems descritos por H. von Förster ${ }^{28}$ e cada identidade é sistema, como cada sistema tem a sua identidade. Palomar, personagem de Calvino, nos explica este tema talvez melhor do que qualquer tratado científico. Não por acaso, Palomar nesta parte da obra está "em sociedade" e, entre as eloquentes condições deste encantador personagem contemporâneo, suspenso no tempo, Italo Calvino enumera e descreve de maneira inigualável "o silêncio". ${ }^{29}$

"O senhor Palomar não consegue falar apressadamente" em uma época como a nossa, na qual nos comunicamos com extrema dificuldade. Fala-se muito, mas se comunica pouco. E comunica-se pouco sobretudo porque as gerações nunca acham um ponto de encontro, ainda que precário. Palomar vive de fato "em uma época na qual a intolerância dos velhos para com os jovens e dos jovens para com os velhos alcançou o seu cume" (a nossa, todas). ${ }^{30}$

A inquietude da época é dada então por esta condição, simétrica e recíproca, na qual as gerações se encontram. A intolerância que as separa é aquela que as une, em um jogo especulativo: “os anciãos não fazem mais do que acumular argumentos para dizer finalmente aos jovens o que eles merecem e os jovens não esperam outra coisa que estas ocasiões para demonstrar que os anciãos não entendem nada” ${ }^{31}$

Jogos especulativos: os méritos de uns são os deméritos dos outros. Todo o jogo está em arrebanhar energia e acumular argumentos para gastar na deslegitimação do outro: gastar o próprio tempo para demonstrar que os anciãos não entendem nada é a confirmação, da parte dos anciãos, de que quem não entende nada são os jovens. O jogo se autoalimenta e

\footnotetext{
${ }^{28}$ Förster, Heinz von. Observing systems. Seaside: Intersystems, 1981.

${ }^{29}$ Calvino, Italo. Palomar. Torino: Einaudi, 1983.

${ }^{30}$ Ibidem, p. 107-109.

${ }^{31}$ Ibidem.
} 
perpetua a si mesmo destas reciprocidades negativas. Tanto uns quanto os outros "são fervorosos demais nas teses que estão sustentando" e prontos demais a observar os outros, para ter tempo de parar e refletir. A capacidade de auto-observação é inversamente proporcional à concentração na observação do outro.

Técnicas conhecidas, que colocam em jogo cada "etnocentrismo" e que nada mais representam, além de um "amor excessivo pelos usos e tradições próprios”, míope e mentiroso.

Assim Palomar, no fervor da luta, tenta sem sucesso ser o interlocutor; ninguém dá atenção àquilo que ele quer dizer e ao "que ele procura clarear para si mesmo”. A sua dificuldade é devida ao fato de ele preferir fazer ou receber as perguntas, mais do que afirmar verdades. Exatamente o contrário do que cada geração faz, quando põe como diferença irrenunciável a própria identidade geracional. Questionar-se no lugar de optar pela própria verdade significa sair fora do jogo das "gerações”, significa observar o "código" das gerações, em vez de observar dentro do próprio código. Problema de qualquer jogo de observação, apto a ampliar o próprio campo somente graças àquela singular estratégia de fuga, que consente enxergar-se como um dos atores, em jogo com os outros, de olhar o jogo, no lugar de olhar dentro do jogo, renunciando assim a cada arrogante, míope e frustrante protagonismo.

O clamor, entretanto, é excessivo, a fim de que a ele seja dada atenção; excessivo como é a sordidez de cada geração, que vive da sua relação irremovível com as outras, mas tende a negá-las, em uma paradoxal condição de ligação dupla.

Melhor do que qualquer outro expert científico sobre o assunto Calvino, por meio do seu personagem, direciona o olhar para o paradoxo da identidade geracional. Esta de fato vive deste código paradoxal, que a constrói sobre a base da sua diferença e dela depende; mas principalmente a faz viver condicionada. Quanto mais sólida, blindada e obstinadamente 
protegida no seu "amor excessivo pelos usos e tradições próprios” for a identidade, mais determinada pela instabilidade e contingências ela será. As gerações passam ou são passadas, mas o dado da mutabilidade não impede a construção de identidades simétricas e opostas. Será possível dizer que ser jovem é um dado passageiro para os indivíduos ou para massas inteiras de atores, mas estável para toda aquela condição que se encontrou, e se encontrará sempre, a compartilhar aquela faixa geracional, mas então não se trata de elaborar identidades e sim de decifrar o modo pelo qual uma cultura se transmite e ultrapassa os limites geracionais. A provisoriedade, contudo, torna-se um problema ainda mais inextrincável, quando o ciclo geracional se expande no tempo e no espaço e acaba por ser o verdadeiro elemento estrutural, que define culturas inteiras.

Justo a provisoriedade sobre a qual se elabora uma identidade sólida, a ponto de se tornar "metafísica" (no sentido da Metafisica della gioventù, de que falava W. Benjamin), ${ }^{32}$ revela todo seu dado paradoxal; o paradoxo não é da observação, que no caso o replica, mas da identidade, que se constrói assim, definitivamente, sobre a "provisoriedade" do pertencimento a uma geração. E é evidente que é diversa a identidade geracional daquela sexual ou daquela geográfica, mas de todas as identidades compartilha os jogos de observação.

\section{O FUTURO DO DIREITO}

A interferência entre o tempo da vida e o tempo do mundo, que desde o início nos guiou ao longo do acidentado terreno das gerações futuras, é a moldura dentro da qual se esteve delineando o problema de uma teoria normativa dos direitos das gerações futuras. Não deve surpreendernos o jogo da normatividade referida aos direitos; não se trata, conforme

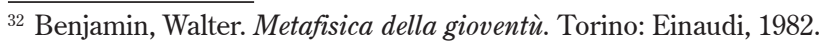


sabemos, de tautologia. Mesmo que uma norma defina como "direitos" aqueles das gerações futuras, coloca-se o problema do âmbito dentro do qual esses se explicam, fazem-se valer alguns limites nos quais operam. Deveria começar-se a discutir, e a resolver, todas as questões que se atêm à natureza e à extensão de tais direitos. Antes de tudo ocorreria superar a dimensão subjectloss dos direitos das gerações futuras, respondendo à pergunta sobre quem possa legitimamente falar "em nome e por conta das gerações futuras" (ou da natureza, ou dos animais e assim por diante). A resposta óbvia da existência de "representantes" de uma parte pode remeter a uma ideia de "esfera pública”, capaz de incluir em si as futuras gerações; de outra parte pode ser "referida" à taxonomia dos "direitos humanos” (dignidade, autodeterminação, liberdade, igualdade, saúde, ambiente). Não vejo dificuldade na referência, sempre em certa medida paradoxal, à esfera pública ou à humanidade. Por isso ocorre mais uma vez uma aproximação $o^{33}$ ao problema, capaz de decompor a "metafísica" (a humanidade pode sozinha ameaçar a si mesma, mas sempre sozinha pode encontrar proteção), mas não basta. A “falar”, e então a representar, em nome das gerações futuras está o presente: a tesoura entre tempo da vida e tempo do mundo retorna como problema. De resto se manteve, não por acaso, que a escolha do presente pelo futuro esconde fatalmente uma cota inevitável de etnocentrismo, correndo então o risco de se representar a vida dos outros com base em parâmetros próprios ou de "atribuir" aos outros os próprios modelos de vida. Isto é de certa forma inevitável; não é sem razão que J. Rawls ${ }^{34}$ mencione altruísmo "moderado", capaz de temperar também tais dificuldades. De outra parte, o inteiro modelo de "troca”, ou seja, da "justiça entre gerações”, impõe superar não somente o modelo da "reciprocidade negativa", mas olhar além do jogo da reciprocidade, fundado sobre direitos que, como vimos, não nos levam a lugar nenhum.

${ }^{33}$ Em italiano ap-prossimazione.

${ }^{34}$ Rawls, J. Op. cit. 1982. 
As incertezas de uma teoria da normatividade construída sobre direitos encontram uma forte especulação em uma mesa de deveres. A contestação do fundamento "contratualista" é já um forte sintoma disso, ligada indissoluvelmente a uma ideia de reciprocidade. Ou os limites, e os relativos deveres, consideram desde já o conteúdo jurídico da esfera do presente, da atualidade, constituindo-lhe as fronteiras a não ultrapassar, ou o vínculo é pouco justificável em "nome das gerações futuras”, ou ainda, é justificável somente sobre outras bases. Pensemos a utilização do princípio da precaução e como as retroações negativas sobre "princípios" do sistema de Direito produzam contradições fortes, dificilmente aceitáveis no plano puramente teórico. Tanto é que em todos os atos normativos que se reportam ao princípio da precaução alude-se a um marco temporal que se refere à proximidade geracional avizinhada: se fala do presente e, talvez por efeito dele, do futuro.

Concordo totalmente com a reconstrução de E. Lecaldano e aceitaria também a sugestão de aprofundar a possível utilização da "proibição do abuso do direito", a respeito da qual permanecem importantes as páginas de Pietro Rescigno. Tanto que na "Carta di Nizza” o artigo final é, não por acaso, dedicado à proibição do abuso do direito. O único problema, que não é imposto pela escassa utilização do princípio, é que o abuso permanece estruturalmente ligado à dinâmica dos direitos do presente: não sai do jogo da reciprocidade.

De maneira mais geral, e também isto é consenso no confronto de E. Lecaldano, existe uma profunda continuidade entre a lógica dos "deveres” e a ética da responsabilidade, ao menos na sua declinação em chave de consequencialismos. Mesmo que a transposição não seja mecânica, pode-se afirmar que exista certa continuidade, ao menos no sentido de que os deveres poderiam representar sanções referidas às ações de êxito moralmente não aceitável. Se se corrige a tese de D. Parfit (utilitarismo 
do ato ${ }^{35}$ com a consequência indireta da regra, tem-se a possibilidade de imputar injustiça a mecanismos que criem sofrimento para as gerações futuras e limitem a sua liberdade. Obviamente não resolvemos o problema, talvez porque os sofrimentos sejam calculáveis só em parte e com base em projeções negativas (não é possível fazer). Pode existir sofrimento tanto porque fazemos quanto porque não fazemos: o exemplo da genética, que é somente um deles, nos transportará sempre ao jogo infinito do caráter ambivalente da técnica e cada risco representará a duplicidade (do fazer e do não fazer, do consentir e do proibir).

Para concluir: até agora dentro das operações do sistema jurídico, com todos os problemas, os vínculos, as "exatidões" da linguagem que isto comporta, pode-se assegurar que, tanto no campo dos direitos, quanto no dos de deveres, a única direção que o senso normativo do Direito nos pode prudentemente sugerir é aquela de obedecer à única regra virtuosa que ele, mesmo historicamente, se deu: tal regra é aquela que salva a diferença do Direito da confusão com outras linguagens substancialistas. Salvar as possibilidades (save the chances), não significa usar lógicas sacrificais, evitar proibições e permissões absolutas, mas sim orientar-se para a maximização da liberdade. Esta, obviamente, deve contemplar não os presentes, mas também aqueles que deverão e poderão escolher. A liberdade é então do "próximo", com tudo aquilo que, em termos de espaço e de tempo, isto comporta.

\section{REFERÊNCIAS}

BENJAMIN, Walter. Metafisica della gioventù. Torino: Einaudi, 1982.

BERGER, P.; BERGER, B.; KELLNER, H. The Homeless Mind: Modernization and Consciousness. New York: Random House, 1973.

BORGES, J. L. Finzioni. Torino: Einaudi, 1995.

${ }^{35}$ Parfit, Derek. Ragione e persone. Milano: Il Saggiatore, 1989. 
CALVINO, Italo. Palomar. Torino: Einaudi, 1983.

CANETTI, Elias. Massa e potere. Milano: Adelphi, 1981.

CIORAN, E. M. La caduta nel tempo. Milano: Adelphi, 1995.

DERRIDA, Jacques. Donare il tempo. Milano: Raffaello Cortina, 1996.

FÖRSTER, Heinz von. Observing systems. Seaside: Intersystems, 1981.

HOFFMANSTAHL, Hugo von. Libro degli amici. Milano: Adelphi, 1980.

JONAS, Hans. Il principio Responsabilità. Torino: Einaudi, 1991.

KAFKA, Franz. O processo. [s.l.: s.n.].

KANT, Immanuel. Idea di una storia universale dal punto di vista cosmopolitic. In: Scritti politici e di filosofia della storia e del diritto. Torino: Utet, 1956. KOSELLECK, Reinhart. Futuro passato. Gênova: Marietti, 1986. MARQUAND, Odo. Antropologia del tempo. In: Intersezioni, XV, n. 3, 1995. MARRAMAO, Giacomo. Minima temporalia. Milano: Il Saggiatore, 1990. NIETZSCHE, F. Dell'utilità e il danno della storia per la vita. Milano: Adelphi, 1981.

NIETZSCHE, Friedrich. Genealogia della morale. Milano: Adelphi, 1989.

PARFIT, Derek. Ragione e persone. Milano: Il Saggiatore, 1989.

RAWLS, John. Political Liberalism. Milano: Edizioni di Comunità, 1994.

RAWLS, John. Una teoria della giustizia. Milano: Feltrinelli, 1982.

RESTA, Eligio. Il diritto fraterno. 6. ed. Roma-Bari: Laterza, 2006.

SARTRE, J.-P. Quaderni per una morale. Roma: Edizioni Associate, 1991.

SCHMITT, Carl. Amleto o Ecuba. Bologne: Il Mulino, 1983.

SÊNECA, Lucius Annaeus. Cartas a Lucílio. [S.1.: s.n.].

WITTGENSTEIN, Ludwig. Osservazioni sui colori. Torino: Einaudi, 1981.

Recebido em: 15/8/2013

Aceito em: 15/8/2013

Autor convidado. 